\title{
Nonlinearities in Economic Growth: A Semiparametric Approach applied to Information Technology data*
}

\author{
Elena Ketteni ${ }^{\dagger}$ \\ University of Cyprus \\ Theofanis P. Mamuneas ${ }^{\ddagger}$ \\ University of Cyprus \\ Thanasis Stengos ${ }^{\S}$ \\ University of Guelph
}

February 2007

\begin{abstract}
The purpose of this paper is to examine the Information and Communication Technology (ICT) capital-economic growth nexus, taking into consideration the previously documented nonlinear relationship between initial income and human capital on the one hand and economic growth on the other. We apply nonparametric techniques for a number of OECD countries for the period 1980-2004. Specification tests provide evidence in favor of the semiparametric specification in which initial income, human capital and ICT capital enter nonlinearly.
\end{abstract}

\footnotetext{
${ }^{*}$ We would like to thank an anonymous referee for the suggestions and comments on the paper which were very helpful.

${ }^{\dagger}$ Department of Economics, University of Cyprus, P. O. Box 20537, CY-1678 Nicosia, (e-mail: ecpgek1@ucy.ac.cy).

${ }^{\ddagger}$ Department of Economics, University of Cyprus, P. O. Box 20537, CY-1678 Nicosia, (e-mail:tmamuneas@ucy.ac.cy)

${ }^{\S}$ Department of Economics, University of Guelph, Guelph, Ontario, Canada N1G 2W1 (e-mail: tstengos@uoguelph.ca).
} 


\section{Introduction}

In recent years economists have debated whether the accumulation of information technology, or generally referred to as information and communication technology (ICT), capital contributes positively to rising income. On the one hand, it is argued that the development of ICT is one of a series of positive temporary shocks and its has a non permanent effect on growth (see for instance, Berndt and Morrison, 1995, Morrison, 1997, Jorgenson and Stiroh, 1999, Jorgenson. 2001 and Gordon, 2000). On the other hand, there is argued that ICT has produced a fundamental change in the economy leading to permanent improvement in growth prospects (see for instance Siegel, 1997, Barua and Lee, 1997, Stiroh, 2002 Biscourp et al, 2002, Matteucci et al., 2005, and Basu et al, 2003).

The purpose of this paper is to examine the effect ICT capital on economic growth, for a number of OECD countries, taking into consideration the previously established relationship among economic growth initial income and human capital.

For the most part, the early empirical growth literature relied on a linear model specification, something that has been challenged by several recent studies, which investigate nonlinear models that allow for multiple regimes of growth patterns among different countries. These models are consistent with the presence of multiple-state equilibria that classify countries into different groups with different convergence characteristics (see Quah, 1996, Durlauf and Johnson, 1995, Hansen, 1996, Lui and Stengos, 1999). In a recent study, Kourtellos (2003), using nonparametric techniques concluded that there exists substantial parameter heterogeneity in the cross-country growth process as well as the presence of multiple steady state equilibria. Papageorgiou and Masanjah (2004) used a CES production function to also explore the issue of nonlinearity and heterogeneity in a parametric framework. Moreover, several researchers have questioned the assumption that human capital exerts the same effect on economic growth both across countries and across time and showed instead that this effect differs according to a country's level of human capital and that there may be important differences in the way human capital affects economic growth as far as educational attainment by gender is concerned (see Kalaitzidakis et al, 2001, Durlauf and Johnson, 1995, Mamuneas, Savvides and Stengos, 2006).

Most of the early evidence based on aggregate US data, suggests that 
ICT and especially computers have had no effect on either productivity or growth (see Berndt and Morrison, 1995, Morrison, 1997, Jorgenson and Stiroh, 1999, Jorgenson, 2001, Gordon, 2000). More recent studies relying primarily on the use of industry or sectoral data indicate that ICT is indeed playing a major role in the productivity of an economy (Siegel 1997, Barua and Lee, 1997, Stiroh ,1998, 2002 and Jorgenson, Stiroh and Ho, 2002). With regard to non US studies, Biscourp et. al. (2002), using a panel of 5000 French firms investigate how the decrease in the cost of computers has affected the marginal cost of firms, their aggregate labor demand and their skill structure and they find a strong but heterogeneous effect across firms. Also Matteucci et al (2005) consider the contribution of ICT to international productivity performance and show that ICT has typically had a lower impact on productivity in Europe than in the US, although there is a considerable variation within Europe. In another paper Basu et al (2003), find in both US and UK a strong correlation between ICT use and industry TFP growth. The US results indicate that the TFP acceleration was located primarily in ICT-using industries and is positively correlated with industry ICT capital growth from the 1980s and early 1990s. In the UK, TFP in the late 1990s is strongly and positively associated with the growth of ICT capital services and with the growth of ICT investment. Finally, Hoon (2003), explores the impact of ICT investment on economic growth using a cross-country analysis based on data from 56 developing countries for the years 1970-1998 and finds that ICT positively contributes to economic growth in the developing world.

The bulk of this research has examined the relationship between ICT and productivity for the US economy or other advanced industrialized countries. However, there is very little research done to examine the impact of ICT on economic growth for a group of countries, something that we do in this paper. This study allows the effects of initial income, human capital and ICT capital to differ both across each country and also across each time period.

We study the impact of ICT capital on economic growth by extending the empirical model developed by Kalaitzidakis et al (2001). We apply recentlydeveloped nonparametric estimation techniques that, while allowing for the well known nonlinear effects of initial income and human capital, investigate nonlinearities in the relationship between economic growth and ICT capi- 
tal for a number of OECD countries for the period between 1980-2004. The results that we obtain are consistent with those of previous studies. We reestablish that initial income and human capital have a nonlinear effect on economic growth, but we also find that there exist a nonlinear relationship between ICT capital and economic growth. Moreover, when taking into consideration the three components of ICT capital, e.g. IT hardware, communication equipment capital and software, and re-estimate the nonparametric model we observe that the nonlinearities still persist as all three ICT capital components appear to have a nonlinear relationship with economic growth. Specification tests provide evidence in favor of the semiparametric model in which initial income, human capital and ICT capital enter nonlinearly.

ICT nonlinearities may arise from country differences in their timing to the approach to the steady state since the growth process is characterized by different stages of development, as well as differences concerning their industry sectors. IT intensive industries which are more likely to exist in countries with high levels of ICT, exhibit different characteristics than conventional industries causing heterogeneous effects.

The paper is organized as follows. Section 2 presents the methodology and the data sources and section 3 the estimation results. Section 4 presents some specification tests and last section concludes.

\section{Methodology and Data Sources}

In this section we briefly present the nonparametric techniques that we use to investigate possible nonlinearities between economic growth and initial per capital income, human capital and information and communication technology capital. Nonparametric regression assumes little about the shape of the regression function beyond some degree of smoothness. The value added of nonparametric techniques is their ability to deliver estimators and inference procedures that are less dependent on functional form assumptions (see Yatchew (1998)). Unfortunately, nonparametric methods also have important drawbacks that are not present in parametric analysis. These the "curse of dimensionality" and the need to select a smoothing parameter.

Perhaps the most severe complication in a purely nonparametric approach is the "curse of dimensionality". Every estimation method has some costs associated with it and, in the case of nonparametrics, it is the need for 
very large samples if an accurate measurement of the unknown (regression) function is to be made. Moreover, the size of the sample required increases rapidly with the number of variables involved in any relation. Such features lead to the proposition that one might prefer to restrict some variables to have a linear impact while allowing a much smaller number to have a nonlinear one. Effectively estimation involves a combination of parametric and nonparametric methods, leading to the estimators being described as semi-parametric.

In order to provide tractability and to overcome the so-called "curse of dimensionality", nonparametric techniques typically impose some structure on the functional form to be estimated. The objective is to estimate the regression function:

$$
y_{i t}=x_{i t} \beta+\theta\left(z_{i t}\right)+\epsilon_{i t}
$$

given data for $y$, and where $x_{i t}$ is a variable of dimension $q, \beta$ is a $q \times 1$ vector of unknown parameters, $z_{i t}$ is a continuous variable of dimension $p$, $\theta($.$) is an unknown function, E\left(\epsilon_{i t} / x_{i t}, z_{i t}\right)=0$, and $\operatorname{Var}\left(\epsilon_{i t} / x_{i t}, z_{i t}\right)=\sigma_{\varepsilon}^{2}$ where $\sigma_{\varepsilon}^{2}=\operatorname{Var}\left(y_{i t} / x_{i t}, z_{i t}\right)$. Robinson (1988) provided a way of obtaining $\sqrt{n}$ consistent estimator of the parameter vector $\beta$ by concentrating out the influence of the nuisance variable $z$ by conditioning on them. Fan, Li and Stengos (1995) derive a $\sqrt{n}$ consistent estimator of $\beta$ allowing for heteroskedastic disturbances. However, such an approach although very useful if one were interested solely in the parameter vector $\beta$, conceals the influence of the $z$ in the regression function. For the problem at hand, there are several ways by which one can approximate the regression function $\theta(z)$. Here, following previous researchers we employ the Partially Additive Linear model, estimated via marginal integration.

\subsection{Marginal Integration and the Partially Additive Linear (PLR) Model}

If one wants to uncover the shapes of the individual components of $z$ (in order to investigate whether nonlinearities exist) it is necessary to impose more structure on the equation to be estimated assuming an additive structure of the unknown components. Yatchew (1998) notes that an additive structure tackles the curse of dimensionality problem and it is more efficient than a general nonparametric structure. For the growth regression model in (1) 
we allow several variables $(z / s)$ to enter nonlinearly including the variable of interest - ICT capital growth rate- as well as initial income and human capital. In general, the PLR model can be written as:

$y_{i t}=x_{i t} \beta+\theta\left(z_{1 i t}, z_{2 i t, . .,} z_{p i t}\right)+\varepsilon_{i t}=x_{i t} \beta+\sum_{\ell=1}^{p} \theta_{\ell}\left(z_{\ell i t}\right)+\varepsilon_{i t}, \quad i=1 \ldots N, t=1 \ldots T$

Linton and Nielsen (1995), and Fan et al. (1996) use marginal integration ${ }^{1}$ to estimate the components of the additive semiparametric partially linear regression (PLR) model in (2).

Applying marginal integration to the additive PLR model, leads to the result that the asymptotic distribution of $\left(\widehat{\theta}_{s}\left(z_{s}\right)-\theta_{s}\left(z_{s}\right), s=1 \ldots p\right)$ is the same as if the other components $\theta_{l}($.$) for l \neq s$ and $\beta$ were known. In other words $\widehat{\theta}_{s}\left(z_{s}\right)$ behaves the same way as if it were a one-dimensional local nonparametric estimator. This is one of the strongest arguments in favor of this method (it amounts to a model with only one nonlinear explanatory variable) against the more traditional nonparametric estimation methods such as nonparametric least squares. In addition, the additive semiparametric PLR allows for a separate treatment of the individual $\theta_{s}\left(z_{s}\right)$ components, and for their graphical representation and their respective pointwise 95 percent confidence intervals to serve as a diagnostic tool to establish any nonlinearities in the shapes of these components. The linear benchmark can be compared to the additive semiparametric PLR and in the case where the linear benchmark lies outside the confidence bounds there is direct evidence of a nonlinear structure not captured by the linear benchmark model.

\subsection{Empirical implementation and Data Sources}

Following Kalaitzidakis et al (2001), we begin our analysis by applying marginal integration to the following PLR model,

$y_{i t}=a_{0}+\sum_{i=1}^{N-1} a_{i} D_{i}+\sum_{t=1}^{T-1} a_{t} D_{t}+a_{3} \ln s_{i t}+a_{4} \ln \left(n_{i t}+\phi+\delta\right)+\sum_{\ell=1}^{3} \theta_{\ell}\left(z_{\ell i t}\right)+\varepsilon_{i t}$

where $y_{i t}$ refers to the growth rate of GDP per capita in each country and for each period, $D_{t}$ and $D_{i}$ are dummy variables for each period and for the

\footnotetext{
${ }^{1}$ The symptotic properties of $\hat{\beta}$ and $\hat{\theta}_{s}\left(z_{s}\right)$ have been derived by Fan, Hardle and Mammen (1996).
} 
countries respectively, $s_{i t}$ is the share of output devoted to non-ICT physical capital accumulation, $n_{i t}$ is the the growth of population, $\phi$ is the rate of exogenous technological change, $\delta$ is the depreciation rate for (human, ICT and non-ICT) capital and $z_{1}, z_{2}$, and $z_{3}$ are the logarithms of the per capita initial income, human capital per effective worker, and ICT capital growth rate per effective worker, respectively ${ }^{2}$.

We then proceed to use the semiparametric PLR model that allows five variables as nonlinear determinants of growth. In addition to initial income $\left(z_{1}\right)$ and human capital $\left(z_{2}\right)$ we disaggregate the ICT capital $\left(z_{3}\right)$ to its constituent parts, that is (i) Information Technology hardware (IT), (ii) Communication Equipment (CE) capital and (iii) Software (S) and use their growth rates in the equation to be estimated.

Equation (3) is estimated using the Gaussian kernel. The choice of bandwidth is given by $c \times s_{Z_{s}} \times m^{-1 / 5}$, where $s_{Z_{s}}(s=1,2,3)$ is the standard deviation of $z_{s}, c$ is a constant, and $m$ is the total number of observations. We used cross-validation to select the value of $c$ in the range 0.8 to 2.0. In addition have calculated $95 \%$ confidence intervals and a linear benchmark (based on a purely linear specification of (3)) to enable us to evaluate nonlinearities in the relationship between these variables and economic growth. In situations where the linear benchmark lies outside the confidence bounds there is evidence of a nonlinear structure not capture by the model.

\subsubsection{Data Sources}

The GDP data concerning the growth of real per capita GDP and the initial GDP were obtained from the World Development Indicators and Penn World Tables. For each individual country we have collected annual data, from 1970 onwards, on the growth rate of real per capita GDP used as the dependent variable in our analysis and GDP per capita from which we constructed the initial GDP variable. We define the initial per capita GDP to be the per capita income at the beginning of each 5 year interval period. That is we use a moving average of 5 years to obtain the initial per capita GDP (i.e. to obtain the initial per capita income of 1980 we use the data on GDP per capita from 1975 to 1980, for 1981 we use the data from 1976 to 1981 etc. $^{3}$ ).

\footnotetext{
${ }^{2}$ For the the theoretical justification of the above model see Mankiw et al. (1992)

${ }^{3}$ We have also used a moving average of 10 years to obtain initial income. The results do not change.
} 
Population data were used in order to obtain $n_{i t}$. To the population growth we add a constant 0.1 that captures the combined effect of the depreciation rate and technological change.

The OECD database provides investment data, that covers a wide range of countries over the period 1980-2004, on IT hardware, Communication equipment, Non-ICT equipment, transportation equipment, non residential structures and software. Non-ICT investment data were used to construct $s_{i t}$. ICT includes IT hardware, Communication equipment and software..

Using a constant depreciation rate $(5 \%)$, capital stocks are constructed for each category of ICT investment using the perpetually inventory method. Therefore, we obtained the IT hardware capital stock, the communication equipment capital stock and the software capital stock used in the estimation analysis. To proceed, we aggregate the data to obtain total ICT capital.

The human capital stock data are obtained and updated from Vikram and Dhareshwar (1993). For a full description of their methodology see Vikram, Swanson and Dubey (1995). Their data covers the period 1950 to 1990 and they define human capital stock as total mean years education. We use extrapolation to update the human capital stock up to 2004 since human capital annual data after 1990 do not exist. For the update of the data we also take into consideration the human capital stock constructed by Barro and Lee (2001). However, we can not directly use the Barro and Lee data for our analysis since their human capital data are calculated in 5 year intervals. We are aware that the extrapolation method may not be the most appropriate, but we are confident that the results obtained using the updated series would be fairly robust as the human capital stock for each country, measured as mean years of education, does not change much throughout the years.

The countries chosen were based on their availability on ICT data as well as human capital data. The sample includes Austria, Belgium, Denmark, Finland, France, Germany, Greece, Ireland, Italy, Netherlands, Portugal, Spain, Sweden, UK and USA for the period between 1980 to 2004.

To sum up, our dataset contains for each country (during the period 1980 to 2004) data on the growth rate of real per capita GDP, the initial per capita GDP, population growth, ICT capital stock as well as the three components of ICT, human capital stock and the share of output devoted to non-ICT. 


\section{Estimation Results}

We begin our analysis with total ICT capital as the third component of the additive model ${ }^{4}$. The estimation results are presented graphically in Figure 1. Figure 1 shows the shapes of the relationship between economic growth and initial income, human capital and total ICT capital. The first graph shows that, in accordance with previous studies, the logarithm of initial income has a nonlinear effect on economic growth. In addition, the second graph shows the relationship between growth and the logarithm of human capital is nonlinear. Both graphs appear to be consistent with previous studies like Kalaitzidakis et al (2001) which has shown that the nonlinear relationship between initial income and growth can be modelled as a fourth degree polynomial and the nonlinear relationship between human capital and growth as a third degree polynomial.

Furthermore, Ketteni (2006) has shown that total ICT capital has a nonlinear effect on total factor productivity growth. This is also verified here, as it can be seen in the third graph. The third graph shows that the logarithm of ICT capital has also a nonlinear effect on economic growth. What we observe from this graph is that the effect for countries with low levels of ICT capital increases up to a point and then starts decreasing. For countries with high levels of ICT capital starts increasing again.

To investigate further this point we proceed to break total ICT capital into its three constituent components and to examine whether each component separately has a nonlinear effect on growth, and if not which of the components is responsible for the nonlinearity appearing in the relationship between the aggregate ICT capital and economic growth. The three components (sometimes used also as measure of information technology capital) of ICT capital are: (i) IT hardware, (ii) communication equipment (CE) capital and (iii) software (S). Here we have included all variables, that is, initial income $\left(z_{1}\right)$, human capital $\left(z_{2}\right)$, IT hardware $\left(z_{3}\right)$, CE capital $\left(z_{4}\right)$ and software $\left(z_{5}\right)$ into the additive model $^{5}$. The results are presented in figure 2 .

The results from figure 2 indicate that the nonlinear relationship be-

\footnotetext{
${ }^{4}$ The estimated coefficients and t-statistics (in parenthesis) of the linear part of the model are $\alpha_{3}=0.585(6.20)$ and $\alpha_{4}=-0.582(-1.3)$.

${ }^{5}$ The estimated coefficients and t-statistics (in parenthesis) of the linear part of the model are $\alpha_{3}=0.529(5.49)$ and $\alpha_{4}=-0.306(-1.6)$.
} 
tween initial income, human capital and growth still holds. Additionally, IT hardware, CE capital and software have a nonlinear relationship with economic growth.

Based on the graphical analysis we can conclude that all three measures of ICT capital (i.e. IT hardware, CE capital and software) have each a nonlinear impact on economic growth and there is no single individual component responsible for the aggregate nonlinearity of ICT capital. From figure 2 we can also observe that the nonlinear relationships between IT hardware and CE capital on the one hand, and economic growth on the other, appear quite similar. We observe that in countries with low level of IT hardware and $\mathrm{CE}$ capital the effect on growth is smaller and it is increasing in countries with high levels of both types of ICT capital. A different picture emerges in the case of software (see figure 2). Even though the nonlinearities do appear, we can see that in countries with low levels of software capital the effect on growth is increasing, then it remains relatively stable in the middle region and starts increasing again in countries with high level of software capital.

The graphical analysis with software capital and growth resembles the graph obtained from using aggregate ICT capital in figure 1. However, at high levels of total ICT capital we observe larger increases in the effect on growth, a fact that can be attributed to all ICT components. Based on the above analysis we can conclude that IT hardware, CE capital and software (S) have a nonlinear effect on economic growth and they all contribute to the overall nonlinear effect of total ICT on growth ${ }^{6}$.

Following the growth literature it can be seen that nonlinearities and jumps are quite important in the analysis of technological change. The nonlinearity appearing in the relationship indicates that the way in which ICT impacts growth differs across countries (or groups of countries). The relationship appears to be complex and the effect differs according to a countrys level of ICT capital. Like in the cross-country regression literature [see Durlauf and Johnson (1995), Masanjala and Papageorgiou (2004) and Kourtellos (2003)] parameter heterogeneity may exist in the sense that the

\footnotetext{
${ }^{6}$ For robustness checks we have also estimated the additive models including each time a different component of total ICT capital. The results appear similar to the ones presented so far and are available upon request. That is all the relationships appear nonlinear even in the case where we separate the three components into three different models instead of one that includes all. Keep in mind though that this models are not correctly specified since the other components are omitted from the analysis.
} 
effect of a change in a particular variable is not the same. Different coefficient estimates emerge per country for the effect of initial income and human capital on growth. This is the case for ICT capital as well. That is, there exists a different relationship between growth and ICT capital in different countries.

Countries with high levels of ICT capital are more likely to have ITintensive industries. As Varian $(2001,2003)$ stated many phenomena, such as economies of scale and network effects, even though they are present in conventional industries they are particular important for IT intensive industries. The different characteristics in the IT intensive industries may be responsible for the different coefficient estimates that emerge in this analysis. The effect appear to vary and depends on each country's level of ICT which is related to its industries.

Another way of stating the above point is to think of nonlinearities as a simple reflection of country differences in their timing to the approach to the steady state. In other words all countries will eventually move from a low growth state to a high growth state but this will happen differently for each country. Then, when observed at a given time interval these economies display differences in their growth characteristics that classify them as poor or rich due to their different positions in their transition to a high growth environment, see Galor (2005). It is the recognition that the growth process is characterized by different stages of development that leads to the observed nonlinearities in the data which simply captures the differential pattern in the timing of the take-off from stagnation to growth across economies.

\section{Specification Tests}

In order to verify the appropriate specification of the relationship estimated we perform, first, a specification test proposed by Li and Wang (1998) ${ }^{7}$. It tests the null hypothesis of a linear regression model against a PLR alternative formulation, as in Robinson (1988). The data are given by $\left\{y_{w}, x_{w}, z_{w}\right\}_{w=1 \ldots N \times T}$ which is distributed as an i.i.d. process. The dimensions of $x_{w}, z_{w}$ are $q$ and $p$ respectively. The null hypothesis is given by:

$$
H_{0}: y_{w}=x_{w} \beta+z_{w} \gamma+u_{w}
$$

\footnotetext{
${ }^{7}$ See Appendix for construction of test.
} 
and the alternative by

$$
H_{1}: y_{w}=x_{w} \beta+\theta\left(z_{w}\right)+u_{w}
$$

where $x_{w}$ contains all the determinants of economic growth except per capita income, human capital and ICT capital and $z_{w}$ contains these three variables. The test statistic is shown by Li and Wang (1998) to have an asymptotic standard normal distribution under $H_{0}$. The value of the $\mathrm{Li}$ and Wang statistic is 3.22 and therefore the null hypothesis of a parametric specification is soundly rejected. This implies that some nonlinearities do exist in the model and they should be taken into account.

We proceed to test for a partially linear specification (conditioned only on three variables, initial income, human capital and ICT capital) against a general nonparametric alternative. This test is used in order to establish whether this model is appropriate when compared to the more general one that conditions upon more explanatory variables and it is a variant of a test by Fan and $\mathrm{Li}$ (1996) and $\mathrm{Li}$ and Wang $(1998)^{8}$. The test statistic follows an asymptotic standard normal distribution under the null hypothesis. The test statistic is 1.217 , suggesting that the null hypothesis of a partially linear specification (semiparametric model conditioned on initial income, human capital and ICT capital) cannot be rejected.

For further robustness we have also performed a number of Wald tests assuming that the nonlinear relationship between initial income and growth can be modelled as a higher (fourth) degree polynomial and the nonlinear relationship between human capital and growth as a third degree one. ${ }^{9}$. As in the estimation analysis $z_{1}$ refers to initial income, $z_{2}$ to human capital and $z_{3}$ to ICT capital. A Wald test $\left(z_{1}, z_{2}\right.$ nonlinear v.s. linear) rejects the linear model in favor of the nonlinear one (the p-value is 0.00001). Therefore, the relationship between growth and initial income and human capital is nonlinear and should be taken into account. Next, a Wald test $\left(z_{1}, z_{2}, z_{3}\right.$ nonlinear v.s. linear) also rejects the linear specification in favor of the nonlinear model that includes initial income, human capital and ICT capital as components of the additive model (the p-value is 0.00001).

\footnotetext{
${ }^{8}$ See Appendix for construction of test.

${ }^{9}$ These degrees of the polynomials have been established as higher order terms were not significant and they are in agreement with the results of Kalaitzidakis et al (2001). Also for ICT we use a third degree polynomial.
} 
Both nonlinear specifications are preferred over the linear model. We then proceed to test which one of the two nonlinear specifications is supported by the Wald test. We have also tested the nonlinear specification where only initial income and human capital enter nonlinearly against the case where initial income, human capital and ICT capital are all nonlinear $\left(z_{1}, z_{2}\right.$ nonlinear v.s. $z_{1}, z_{2}, z_{3}$ nonlinear $)$. The p-value from the Wald test is 0.008 , suggesting evidence in favour of a specification where all three variables $z_{1}, z_{2}, z_{3}$ enter nonlinearly. That is there exists a nonlinear relationship between initial income, human capital and ICT capital on the one hand and economic growth on the other.

\section{Conclusion}

In recent years economists have questioned whether the accumulation of ICT capital contributes positively to rising income growth in various countries. This question has given rise to a vigorous debate among economists. On the one hand, it is argued that the development of ICT is one of a series of positive temporary shocks and it has no effect on growth. On the other hand there is a claim that ICT has produced a fundamental change in the economy, leading to permanent improvements in growth prospects.

The purpose of this paper is to provide an investigation of the ICT capital-economic growth relationship, taking into consideration the previously documented nonlinear relationship between human capital and initial income on the one hand and economic growth on the other and allowing the effects of the above variables along with the effect of ICT capital to differ both across each country and also across each time period.

We apply nonparametric techniques that investigate nonlinearities in the relationship between economic growth and the three measures mentioned above, for a number of OECD countries for the period between 1980-2004. The results from the nonparametric approach used show that initial income and human capital have a nonlinear effect on economic growth. In addition, there is also a nonlinear relationship between ICT capital and economic growth. Moreover, when taking into consideration the three components of ICT capital, i.e. IT hardware, CE capital and software, and re-estimating the model we observe that the nonlinearities still persist. All three ICT capital components appear to have a nonlinear relationship with economic 
growth. Specification tests provide evidence in favor of the semiparametric model in which initial income, human capital and ICT capital enter nonlinearly. Based on the above analysis we can conclude that there exists a nonlinear relationship between initial income, human capital and ICT capital (in its constituent and aggregate form) on the one hand and economic growth on the other. 


\section{Appendix}

\section{A. Construction of the Li and Wang (1998) Test}

Let $\widehat{E}\left(y_{w} / z_{w}\right)$ and $\widehat{E}\left(x_{w} / z_{w}\right)$ be the non-parametric Kernel estimates of $E\left(y_{w} / z_{w}\right)$ and $E\left(x_{w} / z_{w}\right)$ respectively. Under the null hypothesis, $E\left(u_{w} / x_{w}, z_{w}\right)=$ 0 for $w=1 \ldots N \times T$. Therefore, a consistent test statistic can be constructed based on $E\left\{u_{w} E\left(u_{w} / z_{w}\right)\right\}$ since $E\left\{u_{w} E\left(u_{w} / z_{w}\right)\right\}=E\left\{E\left(u_{w} / z_{w}\right)^{2}\right\} \geq 0$ and the equality holds if and only if $H_{0}$ is true.

To obtain a feasible test statistic, we replace $u_{w}$ by $\widehat{u}_{w}$ the least squares residuals from the linear regression given by the null hypothesis. In that case $E\left(\widehat{u}_{w} / z_{w}\right)$ can be consistently estimated using non-parametric Kernel techniques. The test statistic is given by:

$$
J_{n}=n \lambda^{\frac{p}{2}} I_{n} / \sqrt{\widehat{\Omega}}
$$

where $I_{n}=\frac{1}{n(n-1) \lambda^{p}} \sum_{w} \sum_{w=j} \widehat{u}_{w} \widehat{u}_{j} K_{w j}$, and $K_{w j}=K\left(\frac{Z_{w}-Z_{j}}{\lambda}\right)$ is the Kernel function, $\lambda$ is the smoothing (bandwidth) parameter and

$\widehat{\Omega}=\frac{2}{n(n-1) \lambda^{p}} \sum_{w} \sum_{w=j} \widehat{u}_{w}^{2} \widehat{u}_{j}^{2} K_{w j}^{2}$. The test statistic is shown by Li and Wang (1998) to have an asymptotic standard normal distribution under $H_{0}$ or $J_{n} \underset{a}{\sim} N(0,1)$

\section{B. Construction of the Fan and Li (1996) Test}

Fan and $\mathrm{Li}$ (1996) argue that if $u_{w}=y_{w}-x_{w} \beta-\theta\left(z_{w}\right)$, then $E\left(u_{w} / x_{w}, z_{w}\right)$ equals zero if and only if the null hypothesis is true. Let $W_{w}=\left(x_{w}^{\prime}, z_{w}^{\prime}\right)$, where $x_{w}$ and $z_{w}$ are of dimension $p$ and $q$ respectively. It is also true that $E\left[u_{w} E\left(u_{w} / W_{w}\right)\right]=E\left\{\left[E\left(u_{w} / W_{w}\right)\right]^{2}\right\} \geq 0$ and the equality holds iff $H_{0}$ holds. Fan and Li (1996) propose a test statistic for the null based on an estimator of $n^{-1} \sum_{w}\left[u_{w} f_{z w}\right] E\left[u_{w} f_{z w} / W_{w}\right] f\left(W_{w}\right)$, where $f_{z w}=f_{z}\left(z_{w}\right), f_{z}($. is the probability density function of $z_{w}$ and $f($.$) is the pdf of W_{w}$.

The estimator of $u_{w} \widehat{f}_{z w}$ is obtained by a two-step procedure as in Robinson (1988) and Fan, Li and Stengos (1995). In the first step, we estimate $\beta$ as $\widehat{\beta}$ by semiparametric estimation. In addition we estimate $u_{w}$ as $\widehat{u}_{w}=\left(y_{w}-\widehat{y}_{w}\right)-\left(x_{w}-\widehat{x}_{w}\right)^{\prime} \widehat{\beta}$ the residuals after the semiparametric estimation where:

$$
\widehat{y}_{w}=\frac{\left[(n-1) \lambda^{q}\right]^{-1} \sum_{j \neq w} y_{j} K_{w j}^{z}}{\widehat{f}_{z w}}
$$


and

$$
\widehat{x}_{w}=\frac{\left[(n-1) \lambda^{q}\right]^{-1} \sum_{j \neq w} x_{j} K_{w j}^{z}}{\widehat{f}_{z w}}
$$

in which $\widehat{f}_{z w}$ is the corresponding kernel estimator of $f_{z w}$ given by $\widehat{f}_{z w}=$ $\frac{1}{(n-1) \alpha^{q}} \sum_{j \neq w} K_{w j}^{z}$, where $K_{w j}^{z}=K^{z}\left[\left(z_{w}-z_{j}\right) / \alpha\right]$ with $K^{z}($.$) being a product$ Kernel and $\alpha$ a smoothing parameter.

The term $E\left[\widehat{u}_{w} \widehat{f}_{z w} / W_{w}\right] f\left(W_{w}\right)$ is estimated by $\left[(n-1) \lambda^{p+q}\right]^{-1} \sum_{j \neq w}\left[\widehat{u}_{w} \widehat{f}_{z w}\right] K_{w j}$, where $K_{w j}=K\left(W_{w}-W_{j} / h\right)=K\left(\frac{x_{w}-x_{j}}{h}, \frac{z_{w}-z_{j}}{h}\right), K$ is a product Kernel and $\lambda$ is a smoothing parameter. Fan and Li denote their test statistic as

$$
I_{n}=\frac{1}{n(n-1) \lambda^{p+q}} \sum_{w} \sum_{j \neq w}\left[\widehat{u}_{w} \widehat{f}_{z w}\right]\left[\widehat{u}_{w} \widehat{f}_{z j}\right] K_{w j}
$$

Define $T=\frac{n \lambda^{\frac{p+q}{2}} I_{n}}{\sqrt{2} \widehat{\sigma}}$, where $\widehat{\sigma}^{2}=\frac{1}{n(n-1) \lambda^{p+q}} \sum_{w} \sum_{j \neq w}\left[\widehat{u}_{w} \widehat{f}_{z w}\right]^{2}\left[\widehat{u}_{w} \widehat{f}_{z j}\right]^{2} K_{w j}^{2}$. Using the above Fan and $\mathrm{Li}$ (1996) conclude that $T_{a}^{\sim} N(0,1)$ under the null hypothesis. This forms the basis for the following one-sided asymptotic test for $H_{0}$ : reject the null at significance level $\alpha_{0}$ if $T \succ Z_{a_{0}}$ where $Z_{a_{0}}$ is the upper $a_{0}$-percentile of the standard normal distribution. 


\section{References}

Barro, R.J and J.W. Lee (2001). International data on educational attainment: Updates and Implications. CID Working Paper, No. 42.

Barua, A. and B. Lee. (1997). The information technology productivity paradox revisited: A theoretical and empirical investigation in the manufacturing sector. The International Journal of Flexible Manufacturing Systems, 9, 145-166.

Basu, S. Fernald, J. G. Oulton, N. and S. Srinivasan (2003). The case of the missing productivity growth: Or does information technology explain why productivity accelerated in the US but not the UK? NBER working paper, No. 10010.

Berndt, E.R and C.J. Morrison. (1995). High-tech capital formation and economic performance in US manufacturing industries. An exploratory analysis. Journal of Econometrics, 65, 9-43.

Biscourp P. Crepon, B. Heckel, T. and N. Riedinger (2002). How do firms respond to cheaper computers?. Microeconomic evidence for France based on production function approach. January 2002.

Durlauf, S.N and P.A. Johnson (1995). Multiple regimes and cross-country growth behavior. Journal of Applied Econometrics, 10, 365-384.

Fan, J., W. Hardle and E. Mammen. (1996). Direct estimation of low dimensional components in additive models. mimeo.

Fan, Y., Q. Li and T. Stengos (1995). Root-N-Consistent semiparametric regression with conditionally heteroskedastic errors. Journal of Quantitative Economics, 11, 229-240.

Fan, Y. and Q. Li (1996). Consistent model specification tests: Omitted variables, parametric and semiparametric functional forms. Econometrica, 64, 865-890.

Galor O. (2005) The Transition from Stagnation to Growth: Unified Growth Theory, Handbook of Economic Growth, North Holland, S. Durlauf and P. Aghion, eds., pp. 171-293. 
Gordon, R. J. (2000). Does the 'new economy' measure up to the great inventions of the past. Journal of Economic Perspectives, 14(4), 49-74.

Hansen, B. (1996). Sample splitting and threshold estimation. mimeo.

Hoon, Y-S. (2003). Does information technology contributed to economic growth in developing countries? A cross country analysis. Applied Economics Letters, 10 (11), 679-82.

Jorgenson, D. W. (2001). Information technology and the US economy. American Economic Review, 91(1), 1-32.

Jorgenson, D.W. and K. J. Stiroh. (1999). Information technology and growth. American Economic Review, 89(2), 109-115.

Jorgenson, D.W., K.J. Stiroh and M.S. Ho. (2002). Information technology, education and the sources of economic growth across US industries.

Kalaitzidakis, P., Mamuneas, T., Savvides A. and T. Stengos (2001). Measures of human capital and nonlinearities in economic growth. Journal of Economic Growth, 6, 229-254.

Ketteni. E. (2006). Economic Growth, Productivity and Technological Change. Unpublished Ph.D. thesis, Department of Economics, University of Cyprus.

Kourtellos, A. (2003). Modelling Parameter Heterogeneity in Cross-Country Regression Models. manuscript, University of Cyprus.

Li, Q. and S. Wang. (1998). A simple consistent bootstrap test for a parametric regression function. Journal of Econometrics, 87, 45-165.

Linton, O.B. and J.P. Nielsen. (1995). A Kernel method of estimating structural nonparametric regression based on marginal integration. Biometrica, 82, 93-100.

Liu, Z. and T. Stengos. (1999). Nonlinearities in cross country growth regressions: A semiparametric approach. Journal of Applied Econometrics, $14,527-538$.

Mamuneas, T., A. Savvides and T. Stengos. (2006). Economic development and the return to human capital: A smooth coefficient semiparametric approach. Journal of Applied Econometrics, 21, 111-132. 
Mankiw, N. Romer, D and D.N. Weil (1992). A contribution to the empirics of economic growth. Quarterly Journal of Economics, 107, 407-37.

Matteucci, N. O'Mahony, M. Robinson, C. and T. Zwick (2005). Productivity, workplace performance and ICT: Industry and firm-level evidence for Europe and the US. Scottish Journal of Political Economy, 52 (3), $359-86$.

Morrison, C.J. (1997). Assessing the productivity of information technology equipment in US manufacturing industries. The Review of Economics and Statistics, 79(3), 471-481.

Papageorgiou, C and W.H. Masanjah (2004). The Solow model with CES technology: nonlinearities and parameter heterogeneity. Journal of Applied Econometrics, 19, 171-201.

Quah, D.T. (1998). Empirics for economic growth and convergence. European Economic Review, 40(6), 1353-1375.

Robinson, P. (1988). Root-N-Consistent semiparametric regression. Econometrica, 56, 931-954.

Siegel, D. (1997). The impact of computers on manufacturing productivity growth: A multiple indicators-multiple causes approach. The Review of Economics and Statistics, 79(1), 68-78.

Stiroh, K.J. (1998). Computers, productivity and input substitution. Economic Inquiry, 36(2), 175-191.

Stiroh, K.J. (2002). Information technology and the US productivity revival: What do the industry data say?. American Economic Review, 92(5), 1559-1576.

Varian, H.R. (2001). High-Technology industries and market structure. Prepared for the Federal Reserve Bank of St. Louis, Jackson Hole Symposium, August 2001.

Varian, H.R. (2003). Economics of Information Technology. Prepared for the Federal Reserve Bank of St. Louis, Jackson Hole Symposium, August 2001. 
Vikram, N. and A. Dhareshwar (1993). A new database on physical capital stock: Sources, methodology and results. Rivista de Analisis Economico, 8 (1), 37-59.

Vikram, N. Swanson, E. and A. Dubey (1995). A new database on human capital stock in developing and industrial countries: Sources, methodology and results. Journal of Development Economics, 46, 379-401.

Yatchew, A. (1998). Nonparametric regression techniques in economics. Journal of Economic Literature, 36, 669-721. 

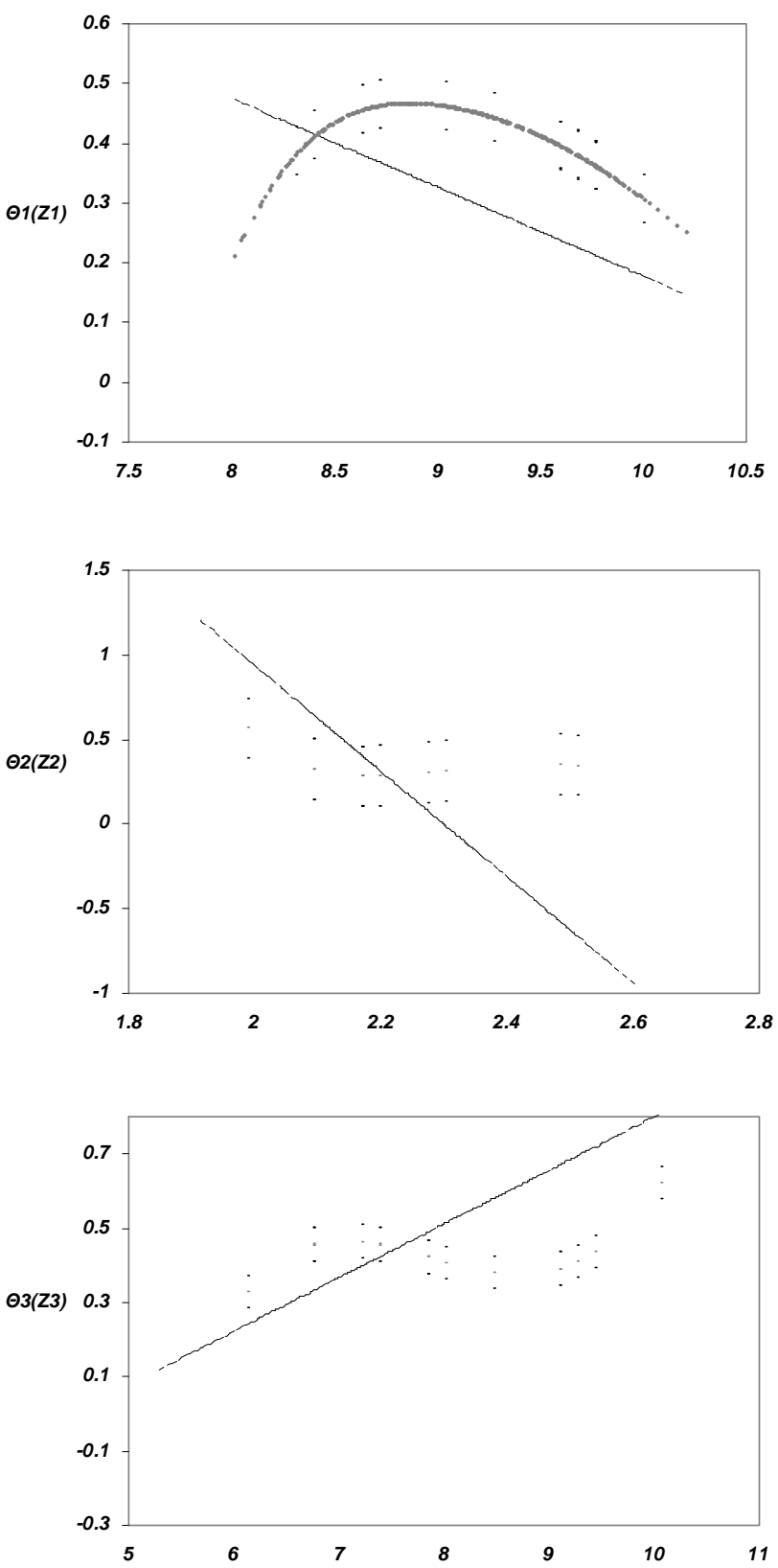

Fig. 1: Semiparametric PLR model conditioned on initial income, human capital and ICT capital. 

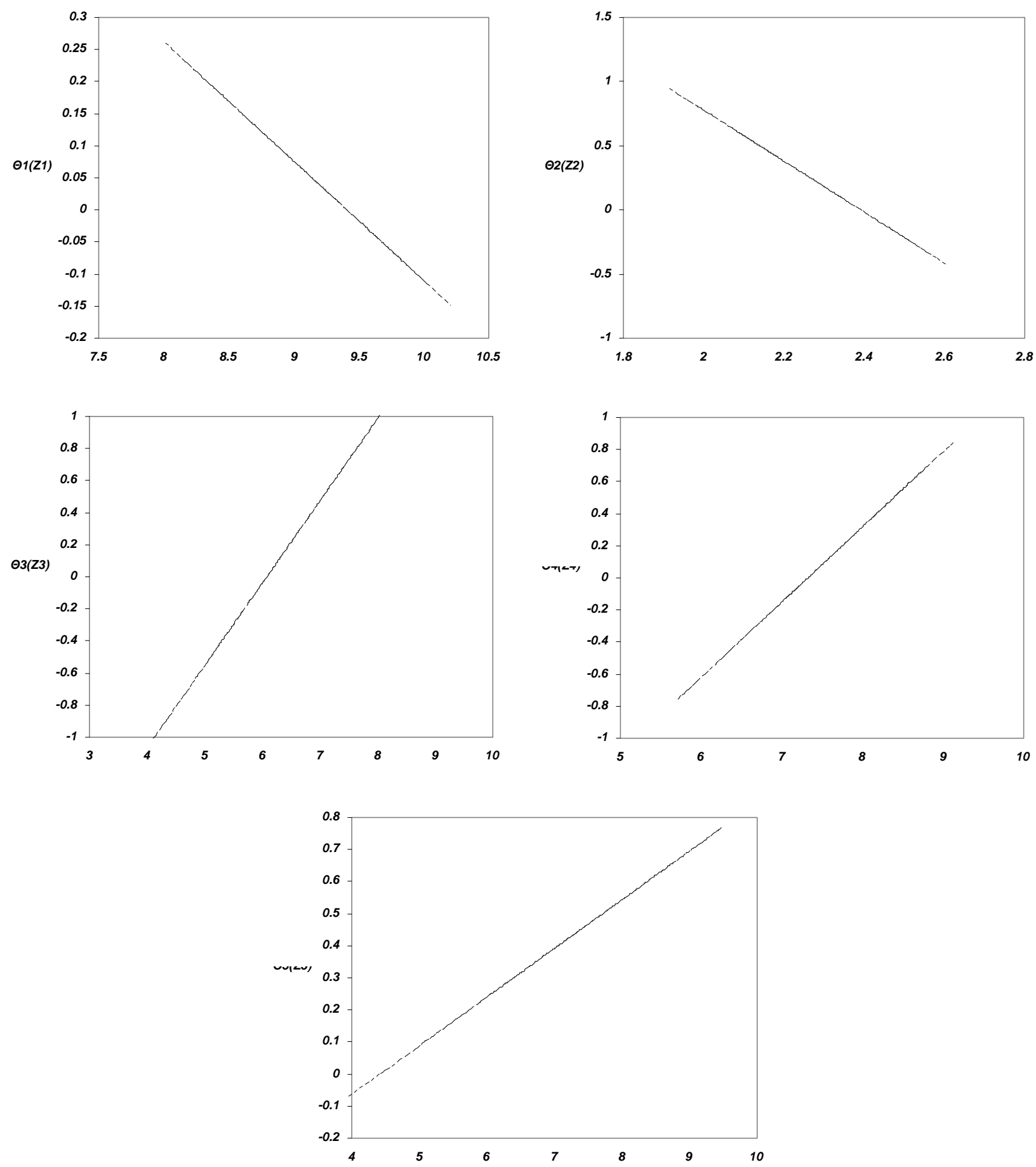

Fig. 2: Semiparametric PLR conditioned on initial income, human capital, IT hardware, CE capital and software. 